would be going too far to put forward the proposition that all cases of co-adaptation may be ultimately explained in the same way, i.e. that they arise from the coalescence (by intercrossing) of $n$ modifications each useful (not useless) in itself, and acquired at successive periods in the phylogeny of the race.

The remarks with which I have endeavoured to meet the arguments advanced by Dr. Romanes ignore the "difficulty" which he have interposed with respect to the want of analogy between artificial and naturai selection. I have leit this out of consideration advisedly, because it raises one of the questions which have so long divided Dr. Romanes from those whom he has thought proper to label "neo. Darwinians." It is the old ciffculty of "the swamping effects of intercrossing " under another form. I do not believe in the reality of this difficulty, and it has been so amply treated of by Dr. Wallace and others that I do not feel warranted in trespassing apon these columns at any greater length in order to rediscuss the question. I can only assure those who have read the comments made upon my review of Mr. Pascoe's book that I have not been made the subject of any metaphorical fraud, but that I accept the analogy between artificial and natural selection as real.

\section{R. MEIDOLA.}

\section{The Meaning of Algebraic Symbois in Applied} Mathematics.

DR. LONGE's remarks on p. $5 \times 3$ ( $\Lambda$ pril 2), ought not, I think, to pass without protest. Ife very reasonalily objects to being asked to use a formula wbich is adapted to one particular set of units, and is not convenient for any other set, and prefers the greater freedom which is usually indulged in, as regards units, in mathematical physics. But he goes further than this, and maintains that it is best (he almost suggests that it is necessary) that Prof, Greenhill's practical man, if he wishes to avoid the somewhat mild difficulties which at present beset him, should adopt the system set forth in NATURE, vol, xxxviit. p. 281 . I may be a reasonable thing to do to base the interpretation of physical equations upon the method of multiplication of concrete quantities described in the article referred to ; but that the praclical man, whose difficulties are in question, is likely to ake the trouble to understand it, may be confidently denied.

However, I think that the system of interpretation advocated involves other inconveniences. Suppcse, for some purpose, we chose to measure the velocity of light by the distance of the light of that colour from a given line in a standard spectrum, thus giving velocity for this purpose the dimension length. This quantity would have different properties from the same velocity measured in the usual way; it would practically be a different guantity; yet the velocity of light is independent of the mode adopted for measuring it. Does it not make confusion to insist upon one of these two quantities being the concrele velocity itself, some other name having to be invented for the other? The same confusion of language would arise even if we desired to depart so slightly from the usual practice as to use our velocity symbol for the specification of it in miles per second, using a centimetre for the unit of length.

I have found that, occasionally, a good way of clearing up difficulties of pupils about dimensions is to say that it is no more intrinsically absurd to equate an area to a length than to equate a length to a product of a velocity and a time, all the symbols being numbers; but that the latter equation can be employed without abandoning the particular freedom as to subsequent choice of units which we wish to retain, and that the former cannot. I have ieard a lecturer appeal, in a similar case, to the intrinsic absurdity of saying that the area of a field is equal to the distance from here to london: this appears to me to be not so clear a way of talking of the distinction between the two cases.

Finally, what are the disadvantages of considering the symbo's of quantity to be mere numbers? Dr. Lodge, while making out his case as agains: Prof. Greenhill, is, to my mind, quite unconvincing on this more general point.

King's College, Cambridge, April II.

\section{Force and Determinism.}

IR. Oirver J. LODGe has reminded us, in your issue of March 26 (p. 491), that under physical constraint or control the direction of motion of material particles may be changed without expenditure of energy or performance of work.
It does not follow from this that the direction of motion can be changed under metaphysical control or constraint-that is to say, by vital force, mind, will-power.

If mind controls the motion of molecules, then mind must be reckoned among the physical forces, differing, however, from all other modes of physical force in that it always acts at right angles to motion.

It is right that your reacers should be informed that there are many philosophers (I atlude especially to those who accept the hypothesis of scientific monism) who regard the supposed control of mind over matter, or of matter over mind, as an assumption which is unnecessary and unsatisfactory.

An arbitrary alteration of the weather might involve no contradiction of the principle of the conservation of energy, and ye at the same time compietely upset our notions of physical causa. tion by the introduction of metaphysical interference.

If the distinction between generating motion and directing motion is one useful to remember, that betwen physical and metaphysical control is still more important.

University College, Bristol.

C. Lloyd Morgan.

The Infiuence of Temperature on the Vagus.

IN Nature of April 9 (p. 548) I notice that Dr. G. N. Stewart says: "nor has the infuence of temperature on the vagus been before studied by a suitabie graphic method." It appears to me that this sweeping assertion is not in accordance with facts, for in my paper upon the "Influence of Temperature on the Pulsations of the Mammalian Heart and on the Action of the Vagus," published in the St. Bartholomew's Hospital Reports for $187 x$, p. 216 , I described a graphic method invented by Prof. Stricker, of Vienna, and employed by me with very satisfactory results. The apparatus may have been ruder than that employed by Dr. Stewart, but the tracings obtained by it were sharp and clear, and allowed the beats of the heart to be easily counted, even when the pulse rate was 470 per minule. The important fact that the peripheral ends of the vagus are not paralyzed by heat, but retain their power to the last, was clearly demonstrated in this paper.

T. LAUDER BRUNTON.

\section{Antipathy of Birds for Coiour.}

Ar this season the yeliow crocus is coming up, and again being destroyed, either playfully or maliciously, by the house sparrow. Has the bird an aversion to yellow? This could be iested by throwing bits of coloured wool about, and finding what colours are used in nesting. I should be glad to learn if this has been tried, and the result.

April I3.

\section{The Discovery of Comet $a$ r $8 \mathrm{gr}$.}

IT is stated that Prof. Barnard, of the Lick Observatory, Mount Hamilion, anticipated me in the discovery of comet $a$ $189 \mathrm{r}$, as he first saw the comet on the evening of March 29 , whereas my observation was made on March 30 . My infor. mation on the point is somewhat meagre and uncertain, but it is very likely to prove correct. If so, I must relinquish my claim to priority, and comfort myself with the reflection that my discovery was an indeperdent one, and that it conveyed the first notification of the comet received by the chief Observatories of Europe.

The Times of April I published a telegraphic message, dated Mount Hamilton, March 31 , as follows:

"A $\leqslant$ mall but fairly bright comet, with a tail of 15 minules in length, was discovered by Prof. Barnard at 8.34 on Tuesday night at the I.jck Observatory, the position being right ascension one hour ten minules and ten seconds, north declination 44 degrees 48 minutes, moving rapidiy southwards in the direction of the sun at the rate of one degree per day."

Now this telegram, if correct, would show that Prof Banard's discovery followed, not preceded, my own (made a 9h. on Monday night, March 30 ), and several scientific journals have alluded to the matter on the basis of the paragraph above quoted. But I think it highly probable the Times' telegram contained several inaccuracies, and that Prof. Barmard first saw the comet on Sunday night, March 29. Further particulars from America will no doubt shortly come to hand. If Prof. Barnard is entilled to priority, let it be freely accorded to him, and he will have my sincere congratulations on another success in a fielcl where he has previously earned sach high distinction. Bristol, April II.
W. F. DENNING.

NO. I $\{20$, VOL. 43$]$ 